\title{
Media devices and sociobehavioral risk factors of conduct disorder in children
}

\author{
Fahad Mukhtar ${ }^{1,2 *}$, Abimbola Michael-Asalu ${ }^{1}$ and Omonigho M Bubu ${ }^{3}$ \\ ${ }^{1}$ Department of Epidemiology and Biostatistics, College of Public Health, University of South Florida, USA \\ ${ }^{2}$ Saint Elizabeths Hospital Department of Behavioral Health Washington DC, USA \\ ${ }^{3}$ NYU Langone Health Department of Population Health \& Psychiatry, 180 Madison Avenue, New York, NY 10016, USA
}

\begin{abstract}
Objective: The use of media devices is high in the United States and has been associated with mental health problems. The aim of this study is to determine the association between exposures to TV and media devices, and conduct disorder in children.

Methods: Data from the National Survey of Children's Health was used to perform a cross-sectional analysis. The Primary outcome was having a previous diagnosis of conduct disorder. We obtained information on total screen time use from exposure to TV, video games, computer devices, and the presence of TV in the bedroom. Use of these devices for more than 2 hours was considered high exposure. Logistic regression model was used to determine the odds ratios between screen time and having a history of conduct disorder.
\end{abstract}

Results: High screen time was associated with higher risks of having a history of conduct disorder (OR=1.45, 95\% CI; 1.04, 2.01) after adjusting for age, sex, parentalchild bonding, arguing, bullying, being sad, engagement in physical activity, family income and race. Moderate and low screen time exposure did not significantly increase the risk of a history of conduct disorder in the adjusted model.

Conclusion: Screen time increases the risk of having a history of conduct disorder. Interventions should be designed to reduce screen time exposure among children.

\section{Introduction}

Conduct disorder is one of the mental health diseases diagnosed in childhood or adolescence characterized by consistent, aggressive behavior and involves violation of fundamental rights of others or societal norms. The Diagnostic Statistical Manual has a set of 15 criteria that are assessed; three criteria are required in a 12 month period to make a diagnosis with at least one being present in preceding six months [1]. These criteria relate to the destruction of property and violation of rights of others [1]. The prevalence of ever having and currently having conduct disorder is $4.6 \%$ and $3.5 \%$ respectively [2]. African American race have the highest prevalence of $8.1 \%$ followed by Whites $(4.2 \%)$. It is more common in male (6.2\%) children and adolescent children within the ages 12 to 17 years old (5.7\%) compared to females and younger children respectively [2]. Parents of children with conduct disorder tend to have a low education level and low-income level [2]. Conduct disorder is an important mental health condition due to its aggressive nature, its coexistence with criminal activities and other social and behavioral health conditions including but not limited to substance abuse, depression and suicidal attempt [3-6].

With respect to mental disorders, studies suggest that media misuse is associated with aggressive, delinquent and antisocial behavior. Media misuse is generally defined as use of media devices for more than 2 hours per day [7-9]. Media misuse has been associated with antisocial behavior in children $(\beta=0.180(0.026-0.333))$ [10], aggressive behavior $(r=0.18, P<.01)[11]$, criminal convictions (adjusted OR=1.27 (1.001.61) [11], conduct problems (1.91 (1.28-2.83)) [12] and externalizing problems (delinquent and aggressive behaviors) $(\mathrm{P}=0.007)$ [7]. Due to increasing media use in childhood and adolescence, [13-15] and the long lasting impact of conduct disorder, it is important to gain more knowledge about how media misuse is associated with conduct disorder.

Other than media use, other risk factors could independently affect both media use and conduct disorder in children. Male children are more likely to develop conduct disorder [16,17] and have more exposure to media devices than females [10,11]. Older children and African American children have higher duration of TV viewing compared to younger children and other racial groups respectively [15]. Both television viewing and aggressive behavior are more likely to be found in neglected children and children from low income families [17]. Conduct disorder and media misuse is more likely to occur in children who bully $[18,19]$. Even though children with conduct disorder are aggressive and tend to argue, they may still exhibit sad or depressive affect [20]. Media misuse is also associated with sadness and may represent a way of coping or channelling the negative emotion associated with sadness [21,22]. Poor parental bonding and lack of caring for children is associated with conduct disorder [10,23,24], while improved parental bonding reduces media misuse in children [25]. Engagement in some form of physical activities on the other hand,

${ }^{\star}$ Correspondence to: Fahad Mukhtar, Department of Epidemiology and Biostatistics, College of Public Health, University of South Florida, Saint Elizabeths Hospital DBH 1100 Alabama Avenue SE, Washington DC 20032, USA, E-mail: fahad.mukhtar@dc.gov

Received: September 12, 2018; Accepted: September 20, 2018; Published: September 24,2018 
protects against conduct disorder in children [26,27] and reduces the amount of television viewing among children [28]. Television and media devices in general may be playing the role of a mediator and exacerbate the risk of conduct disorder in children with these risk factors. $[17,29]$. In this study, we look at the association between media use and conduct disorder while controlling for these important risk factors.

To summarize, it has been shown that media misuse is associated with a lifetime diagnosis of conduct disorder. However, to our knowledge, most of the studies were done outside the United States [7,11,30-33] and did not adequately control for confounding variables such as bullying, arguing and sadness $[7,33,34]$. The aim of this study is to test the hypothesis that exposure to media devices including TV, the internet and mobile phones as measured by screen time increases the risk of conduct disorder in a representative sample while controlling for social and behavioral risk factors.

\section{Methods}

\section{Study population}

Data from the National Survey of Children's Health (2011), a survey on children's health conducted by the Center for Disease Control (CDC) from February 2011 to June 2012, were used to perform a crosssectional analysis. The survey contains both national and state level information based on variables that were focused on behavioral and physical health conditions, demographic data, family health, access to health care and information on child's surrounding neighborhood and characteristics [35]. The survey was conducted using a random digit sampling technique and conducted via a computer-assisted telephone interview (CATI) $[35,36]$. Households that do not have children under the age of 17 were not interviewed $[35,36]$. Only one child was selected per household, and the interviewee would be the person/caregiver most knowledgeable about the health status of the child. Households were selected from sampling areas used in the National Immunization sampling survey which is a survey of immunization coverage in the US [35]. A total of 95,677 interviews were conducted in the entire US, and approximately 1,850 were conducted per state [36]. The data is weighted to represent the population of non-institutionalized children under 17 years in each state and in the entire US [36]. The weights used for the data were adjusted for base sampling weight, quarterly sample weights, multiple telephone lines, lack of coverage of children in houses without landline telephones, and a raking adjustment to external control totals [35]. Further details on the methodology of the NSCH survey has been discussed elsewhere [35,36].

Our analysis was restricted to children between 6 to 17 years because they were the only group questioned about screen time. Nonspecific responses, unknown values and those who refused to answer were recoded as missing. Missing observations were excluded from the analysis.

\section{Variable Selection}

Dependent Variable: This variable was answered by asking the caregiver the following NCSH question: "Now I am going to read you a list of conditions. For each condition, please tell me if a doctor or other health care provider ever told you that [S.C.] had the condition, even if [he/she] does not have the condition now". Several medical conditions were then asked, and this included the outcome variable conduct disorder. Those who answered "Yes" to a previous diagnosis of conduct disorder were recoded as 1 and those who answered "No" were recoded as 0 .
Main Predictor: There were three independent variables that were used to measure exposure to screen time:

a. "On an average weekday, about how much time does [S.C.] usually spend in front of a TV watching TV programs, videos, DVDs, or playing video games?" which was dichotomized to greater than two hours and less than two hours in keeping with the American Academy of Pediatrics guidelines [9] and subsequently given a score of ' 1 ' and ' 0 ' respectively;

b. "On an average weekday, about how much time does [S.C.] usually spend with computers, cell phones, handheld video games, and other electronic devices, doing things other than schoolwork?" dichotomized as above with a score of ' 1 ' and ' 0 '.

c. "Does [he/she] have a TV, computer, or access to electronic devices in [his/her] bedroom?" which was recoded as ' 1 ' and ' 0 ' for those who answered "Yes" and "No" respectively.

The three exposure variables were then used to create a composite exposure variable called screen time. The three variables were added up for a score of $3,2,1$, and 0 corresponding to high, moderate, low and no screen time exposure respectively.

Confounders: Below is a summary of confounding variables and how they were obtained.

a. Age was collected as a continuous variable and was based on the child's age at the time of the interview.

b. Race and ethnicity were determined from two questions: "Is [S.C.] of Hispanic, Latino or Spanish origin?" and "Is [S.C.] White, Black or African American, American Indian, Alaska Native, Asian, or Native Hawaiian or other Pacific Islander?"

c. Income level: The NSCH collected data on income level which were categorized into groups based on Federal Poverty level (FPL) into greater than $400 \%, 200 \%$ to $399 \%, 100 \%$ to $199 \%$, and $0 \%$ to $99 \%$ FPL.

d. Sex of child was obtained by asking "Is [S.C.] male or female?"

e. Parental bonding was based on the question "How well can you and [S.C.] share ideas or talk about things that really matter?"

f. Emotional or aggressive behaviors: We included responses to questions that asked about bullying or cruelty ("[He/She] bullies or is cruel or mean to others?"), disagreement/argument ("[He/ She] argues too much?") and sadness ("[He/She] is feeling sad or depressed?")

g. Engagement/Activities was a derived variable that measures a child activity and was obtained from the response to three questions relating to activities after school which included: sports, organizational activities and other organized activities like music, dancing language, or arts. Children were categorized into two categories comprising of those involved in " 1 or more activity" and "no activity."

\section{Statistical analysis}

Because the data from the survey were unweighted, weights available in the data set were applied to get the actual number of observations. The weighted proportions for each of the categorical independent variables were calculated, and the difference between the categories was assessed using Rao-Scott chi-square statistics. Univariable and multivariable logistic regression were used to obtain unadjusted and adjusted odds ratios between screen time and conduct disorder. The odds ratios were 
adjusted for age, sex, race, federal poverty level, parent-child bonding, extracurricular activities and antisocial behavior as described above. Analyses were conducted using SAS 9.3 (SAS Institute Inc, Cary, NC). $\mathrm{P}$-values of less than 0.05 were considered statistically significant.

\section{Results}

\section{Descriptive characteristics}

There was a total of 65,680 children between the ages of 6 to 17 that were analyzed representing 49,586,134 US children. The mean age and standard deviation were $11.7 \pm 3.5$. Table 1 is a summary of the descriptive characteristics of the sample analyzed. Only weighted statistics are shown. Bivariate analysis showed that children with a history of ever having a conduct disorder were more likely to have higher screen time $(10.1 \%)$ compared to no screen time $(3.4 \%)$. The opposite was observed for children with no previous history of conduct disorder where there was a higher proportion of children with no screen time (96.6\%) compared to high screen time (89.9\%). Overall most of the children had low (41.2\%) or no screen time exposure $(34.6 \%)$. Overall, all the children in our analysis were more likely to be Whites $(53.7 \%)$ followed by Hispanics (22.3\%). There were slightly more males than females ( $51.2 \%$ vs. $48.8 \%$ ), and males were more likely than females to have a history of conduct disorder (6.6\% vs. $3.1 \%)$. Analysis showed that $29.1 \%$ of the children belong to households with greater than $400 \%$ FPL, with the least proportion of $20.7 \%$ belonging to households with less than $100 \%$ FPL. However, stratified by conduct disorder, children with a history of conduct disorder were more likely to belong to households with less than 100\% FPL rather than households with greater than $400 \%$ FPL. Our analysis also showed that most of the children never bullied (61.1\%), sometimes argue $(41.1 \%)$, never reported being sad (43\%), bonded very well (70.4\%) and engaged in 1 or more activities $(80.8 \%)$. (Table 1 )

\section{Logistic regression}

Table 2 presents the result of the unadjusted and adjusted models. Our analysis showed that screen time is associated with higher odds of ever having a history of conduct disorder in both bivariable and multivariable analysis which controlled for age, sex, income level, the level of activity and variables that measure children's behavior including bonding, arguing, sadness, engagement in activities and bullying. In the unadjusted model, having a history of conduct disorder was associated with low $(\mathrm{OR}=1.38,95 \% \mathrm{CI} ; 1.13,1.70)$, moderate $(\mathrm{OR}=1.86,95 \% \mathrm{CI} ; 1.48,2.34)$ and high $(\mathrm{OR}=3.17,95 \% \mathrm{CI}$; $2.41,4.16)$ screen time exposure. Compared to children with no screen time exposure, high screen time exposure was significantly associated with ever having a history of conduct disorder in the adjusted model $(\mathrm{OR}=1.45,95 \% \mathrm{CI} ; 1.04,2.01)$. Moderate and low screen time exposure were not significant in the adjusted model (Table 2).

The multivariable logistic regression analysis showed multiple demographic and behavioral risk factors were associated with conduct disorder. Hispanics, females and belonging to a household with greater than $400 \%$ FPL were significantly associated with lower risk of having a history of conduct disorder. There was a graded dose response between bullying and history of conduct disorder where children who always bullied had the highest odds ratio ( $\mathrm{OR}=5.91,95 \% \mathrm{CI} ; 3.94,8.86)$ while children who bullied rarely $(\mathrm{OR}=1.56,95 \% \mathrm{CI}$; $1.23-1.97)$ had the lowest. Similar pattern was observed for variables which measured argument and bonding (Table 2). Being sad was associated with higher odds of having a history conduct disorder. However, children who were usually sad had a higher odds ratio $(\mathrm{OR}=5.09,95 \% \mathrm{CI} ; 2.99,8.65)$
Table 1. Parent-reported descriptive characteristics of child and household

\begin{tabular}{|c|c|c|c|c|}
\hline & \multicolumn{4}{|c|}{ Conduct disorder conduct disorder } \\
\hline & & Yes & No & \\
\hline $\begin{array}{l}\text { Main } \\
\text { independent } \\
\text { variables }\end{array}$ & $\begin{array}{l}\text { Total, } \\
\text { Weighted (\%) }\end{array}$ & Weighted \% & Weighted \% & p-value* \\
\hline Screen time & & & & $<0.0001$ \\
\hline None & 34.6 & 3.4 & 96.6 & \\
\hline Low & 41.2 & 4.7 & 95.3 & \\
\hline Moderate & 17.1 & 6.2 & 93.8 & \\
\hline High & 7.1 & 10.1 & 89.9 & \\
\hline Race & & & & 0.03 \\
\hline White & 53.7 & 4.8 & 95.2 & \\
\hline Black & 14.2 & 6.4 & 93.6 & \\
\hline Hispanic & 22.3 & 4.6 & 95.4 & \\
\hline Other & 9.7 & 4.3 & 95.7 & \\
\hline Sex & & & & $<0.0001$ \\
\hline Female & 48.8 & 3.1 & 96.9 & \\
\hline Male & 51.2 & 6.6 & 93.4 & \\
\hline $\begin{array}{l}\text { Household } \\
\text { income }\end{array}$ & & & & $<0.0001$ \\
\hline$<100 \%$ FPL & 20.7 & 8.4 & 91.6 & \\
\hline 100-199\% FPL & 21.4 & 6.1 & 93.9 & \\
\hline 200-399\% FPL & 28.9 & 4.1 & 95.9 & \\
\hline$>400 \%$ FPL & 29.1 & 2.3 & 97.7 & \\
\hline Bully & & & & $<0.0001$ \\
\hline Never & 61.1 & 2.2 & 97.8 & \\
\hline Rarely & 24.3 & 4.8 & 95.2 & \\
\hline Sometimes & 12.4 & 13.0 & 87.0 & \\
\hline Usually & 1.2 & 29.0 & 71.0 & \\
\hline Always & 1.0 & 42.1 & 57.9 & \\
\hline Argue & & & & $<0.0001$ \\
\hline Never & 15.4 & 1.3 & 98.7 & \\
\hline Rarely & 24.4 & 1.6 & 98.4 & \\
\hline Sometimes & 41.1 & 3.2 & 96.8 & \\
\hline Usually & 10.3 & 10.3 & 89.7 & \\
\hline Always & 8.9 & 22.1 & 77.9 & \\
\hline Sad & & & & $<0.0001$ \\
\hline Never & 43.0 & 1.9 & 42.1 & \\
\hline Rarely & 34.2 & 3.6 & 33.0 & \\
\hline Sometimes & 20.3 & 10.6 & 18.1 & \\
\hline Usually & 1.8 & 29.5 & 1.2 & \\
\hline Always & 0.8 & 22.7 & 0.6 & \\
\hline Bonding & & & & $<0.0001$ \\
\hline Very well & 70.4 & 3.1 & 96.9 & \\
\hline Somewhat well & 26.3 & 6.9 & 93.1 & \\
\hline Not very well & 2.4 & 24.3 & 75.7 & \\
\hline Not well at all & 0.9 & 35.6 & 64.4 & \\
\hline Engagement & & & & $<0.0001$ \\
\hline No activity & 19.2 & 8.6 & 91.4 & \\
\hline $\begin{array}{l}1 \text { or more } \\
\text { activity }\end{array}$ & 80.8 & 4.0 & 96.0 & \\
\hline Note: Significa & e level deterr & d by Rao-S & Chi-square, & \\
\hline
\end{tabular}

compared to children who were always sad $(\mathrm{OR}=2.24,95 \% \mathrm{CI} ; 1.21$, 4.13). Lack of engagement in physical activity was associated with an increased odds of having a history of conduct disorder ( $\mathrm{OR}=1.48,95 \%$ CI; 1.19, 1.85)

\section{Discussion}

Our study's main objective was to investigate the association between media misuse and conduct disorder in children while determining the role that could be played by factors like the child's 
Table 2. Multivariable and univariable logistic regression model for conduct disorder in 6 to 17 year olds

\begin{tabular}{|c|c|c|}
\hline Independent Variables & $\begin{array}{l}\text { Crude Odds } \\
\text { OR }(95 \% \text { CI })\end{array}$ & $\begin{array}{l}\text { Full Model } \\
\text { Adjusted Odds } \\
\text { OR (95\% CI) \# }\end{array}$ \\
\hline \multicolumn{3}{|l|}{ Screen time } \\
\hline None & Ref. & Ref. \\
\hline Low & $1.38(1.13-1.70)$ & $1.17(0.93-1.47)$ \\
\hline Moderate & $1.86(1.48-2.34)$ & $1.04(0.81-1.35)$ \\
\hline High & $3.17(2.41-4.16)$ & $1.45(1.04-2.01)$ \\
\hline \multicolumn{3}{|l|}{ Race } \\
\hline White & Ref. & Ref. \\
\hline Black & $1.34(1.10-1.63)$ & $0.88(0.69-1.11)$ \\
\hline Hispanic & $0.95(0.73-1.25)$ & $0.70(0.51-0.95)$ \\
\hline Other & $0.89(0.70-1.12)$ & $0.79(0.60-1.03)$ \\
\hline \multicolumn{3}{|l|}{ Sex } \\
\hline Female & Ref. & Ref. \\
\hline Male & $2.16(1.82-2.58)$ & $2.25(1.87-2.72)$ \\
\hline \multicolumn{3}{|l|}{ Household income } \\
\hline$<100 \% \mathrm{FPL}$ & $1.42(1.16-1.74)$ & $1.24(0.97-1.59)$ \\
\hline $100-199 \%$ FPL & Ref. & Ref. \\
\hline $200-399 \%$ FPL & $0.66(0.52-0.84)$ & $0.82(0.63-1.08)$ \\
\hline$>400 \%$ FPL & $0.36(0.28-0.46)$ & $0.55(0.42-0.73)$ \\
\hline \multicolumn{3}{|l|}{ Bully } \\
\hline Never & Ref. & Ref. \\
\hline Rarely & $2.24(1.80-2.80)$ & $1.56(1.23-1.97)$ \\
\hline Sometimes & $6.65(5.38-8.22)$ & $2.58(2.04-3.28)$ \\
\hline Usually & $18.17(11.76-28.10)$ & $3.09(1.85-5.16)$ \\
\hline Always & $32.25(21.69-47.95)$ & $5.91(3.94-8.86)$ \\
\hline \multicolumn{3}{|l|}{ Argue } \\
\hline Never & Ref. & Ref. \\
\hline Rarely & $1.20(0.77-1.89)$ & $1.16(1.23-1.97)$ \\
\hline Sometimes & $2.42(1.71-3.42)$ & $1.64(1.13-2.38)$ \\
\hline Usually & $8.49(5.91-12.20)$ & $3.77(2.52-5.63)$ \\
\hline Always & 21.07(14.89-29.81) & $5.90(3.93-8.86)$ \\
\hline \multicolumn{3}{|l|}{ Sad } \\
\hline Never & Ref. & Ref. \\
\hline Rarely & $1.91(1.49-2.46)$ & $1.68(1.29-2.17)$ \\
\hline Sometimes & $6.17(4.88-7.80)$ & $3.05(2.38-3.89)$ \\
\hline Usually & $21.67(14.06-33.36)$ & $5.09(2.99-8.65)$ \\
\hline Always & $15.21(9.48-24.40)$ & $2.24(1.21-4.13)$ \\
\hline \multicolumn{3}{|l|}{ Bonding } \\
\hline Very well & Ref. & Ref. \\
\hline Somewhat well & $2.29(1.92-2.73)$ & $1.32(1.09-1.61)$ \\
\hline Not very well & $9.97(7.23-13.75)$ & $2.51(1.69-3.73)$ \\
\hline Not well at all & $17.13(11.04-56)$ & $5.22(2.19-12.39)$ \\
\hline \multicolumn{3}{|l|}{ Engagement } \\
\hline 1 or more activity & Ref. & Ref. \\
\hline No activity & $2.23(1.87-2.68)$ & $1.48(1.19-1.85)$ \\
\hline Age & $1.03(1.01-1.05)$ & $1.02(0.98-1.04)$ \\
\hline
\end{tabular}

age, race, sex, household income, bullying, arguing, sadness, bonding and engagement in activities, in the association. To our knowledge, our study is the first to consider the role of these factors in relation to media misuse. In our analysis of data from the large, National Children's Health Survey, we have identified high screen time exposure, behavioral and social risk factors for conduct disorder.

Exposure to high screen time, as defined by the AAP, is associated with ever or currently having a diagnosis of conduct disorder. Our results are consistent with other studies $[7,10,11]$. Youseff et al. found that children who were exposed to TV or video games more than 2 hours per day were at a higher risk of having delinquent or aggressive behavior after adjusting for birth order and siblings number [7]. Another study in New Zealand found that exposure to TV during childhood was associated with higher risk of criminal convictions later on during adulthood and having antisocial personality disorder [11]. Theories that have been put forward to explain the association between media misuse and conduct disorder suggest that children exposed to media may imitate violence, develop beliefs and cognitions that encourage aggression, and exposure to media may transform what should be a negative emotional response to a violent behavior (desensitization) $[37,38]$. We did not find an association between moderate or low screen time exposure and conduct disorder in the multivariate model, which may be indicative that mild exposure to media devices may not be associated with conduct disorder. Apart from the consistency with previous studies, we were able to analyze the effect of different levels of screen time exposure on conduct disorder and we controlled for important risk factors, all of which increase the strength of our analysis.

In terms of demographic and social characteristics, we found that males were more likely to have a history of conduct disorder compared to females which is consistent with other studies [16]. We found that African American children had the highest frequency of exposure to high screen time (14.71\%) followed by Hispanics which was $6.14 \%$. We were also able to show that children from households with high income and of Hispanic race were at significantly lower risk of having conduct disorder compared to others with low-income level and non-Hispanic Whites respectively. In addition, those with the lowest income level at $0-99 \%$ FPL also had the highest proportion of high screen time exposure (9.72\%). These sub-groups with the highest exposure and relatively higher risk could be the target of interventions on reducing conduct disorder.

We also noted that emotional and behavioral conditions like arguing, bullying, sadness, and bonding between parent and child are associated with a history of having a diagnosis of conduct disorder. There was a graded response between these variables and having a history of conduct disorder such that children had higher risks of having a conduct disorder when they were reported to have higher episodes of these behaviors or emotions. Our results, however, showed that being sad was associated with having a conduct disorder but the response was not entirely linear. Children who were reported to be sad "always" were less likely to have conduct disorder compared to children who reported being sad "sometimes" or "usually." This may be because the children that are always sad have lower energy and are more apathetic than those who are less sad, and as a result are less likely to be aggressive or delinquent. However, it is also more difficult for parents to accurately report internalizing behaviors in children like sadness or social withdrawal, as such, children are more likely to be misclassified with regards to their internalizing behavior compared to their externalizing behaviors [39,40].

Since this study has shown that engagement in activities (organizational, sports and organized activities) reduces the risk of conduct disorder, a program that encourages physical activity in children could be an intervention strategy that can be applied. A study found that involvement in high school sports reduced the association between conduct disorder and antisocial behavior $(\mathrm{p}<0.001)$ [27]. Several other interventions have been tested and proven to be effective [41-43]. A randomized control study found a significant reduction in screen time use among children in the intervention group who were exposed to alternative activities other than TV use at school including musical activities, take home activities to do with parents, social 
and writing skills [41]. The percentage of children who viewed TV for more than two hours per day decreased from $33 \%$ to $18 \%$ in the intervention group and it increased from $41 \%$ to $47 \%$ in the control group [41]. Another randomized study used behavioral intervention to counsel parents on how to control the child's use of media devices. They were also given a TV parental control device that helps regulate the amount of TV viewing. Children in the intervention group had a greater reduction in screen time use compared to the control group [43]. A study that used a school-based intervention to teach third and fourth grade students how to reduce their TV exposure and increase their control on TV exposure found significant reduction in peer-rated aggression $(\mathrm{p}=0.03)$ and verbal aggression $(\mathrm{p}=0.01)$ of the children in the intervention group compared to the control group [42]. The American Academy of Pediatrics also has various recommendations that encourage healthy media use among children which include controlling the type and duration of media use in children, having media free times and media free locations, promoting adequate sleep, physical activity, and family interactions [44].

Our study has some limitations. We were not able to account for temporality so we cannot conclude whether conduct disorder preceded exposure to TV and media devices. However, a previous study found a high association between aggressive behavior and television viewing after controlling for previous history of aggressive behavior [17]. Our variables relied on the ability of the caregiver to recall information about their children. Hence, there is a possibility of information or recall bias especially for information regarding the measurement of exposure and outcome variable. However, exposure to TV viewing is more likely to be underestimated because it measures TV viewing on weekdays when children are less likely to watch TV [45]. Also, caregivers are more likely to underestimate TV viewing if the child has a TV in the bedroom $[46,47]$. The diagnosis of conduct disorder relied on caregivers report and was not confirmed by physician or hospital data. Lastly, we had no information regarding the content that was viewed on media devices and TV. Nonetheless, the study has the advantage of having a very large sample size and provided us with significant statistical power to study our hypothesis.

In conclusion, we were able to show that exposure to media devices and TV in children are associated with higher risks of having a history of conduct disorder. This study also identified additional risk factors that may be associated with conduct disorder in children. Future studies may be required to identify predictors of excessive exposure to TV and other media devices in children. The result of this study points to a possible population sub-group that could be targeted for intervention at reducing exposure to TV and media devices and subsequently reducing conduct disorder in children. This intervention would involve the participation of various stakeholders including parents/families, pediatricians, school teachers, researchers, government organizations and industry. Despite the risks of exposure to TV and electronic media devices identified, it is also worth mentioning that they have some benefits: media devices may serve as means of providing social support for children with disabilities [48]; media could be valuable source of health information even for adolescents [49]; the media also can be used to improve healthy behaviors such as quitting smoking [50].

\section{Compliance with Ethical Standards}

\section{Conflict of interest}

No conflict of interest to declare.

\section{Funding}

None declared.

\section{Informed Consent}

Informed consent was obtained from all individual participants included in the study.

\section{Ethical Approval}

All procedures performed in studies involving human participants were in accordance with the ethical standards of the institutional and/ or national research committee and with the 1964 Helsinki declaration and its later amendments or comparable ethical standards.

\section{References}

1. American Psychiatric Association (2013) Diagnostic and Statistical Manual of Mental Disorders (DSM-5®): American Psychiatric Pub.

2. Perou R, Bitsko RH, Blumberg SJ, Pastor P, Ghandour RM, et al. (2013) Mental health surveillance among children--United States, 2005-2011. MMWR Suppl 62: 1-35. [Crossref]

3. Frick PJ, Stickle TR, Dandreaux DM, Farrell JM, Kimonis ER (2005) Callousunemotional traits in predicting the severity and stability of conduct problems and delinquency. J Abnorm Child Psychol 33: 471-487. [Crossref]

4. Frick PJ, McMahon RJ (2008) Child and adolescent conduct problems. A guide to assessments that work: 41-66.

5. Odgers CL, Caspi A, Broadbent JM, Dickson N, Hancox RJ, et al. (2007) Prediction of differential adult health burden by conduct problem subtypes in males. Arch Gen Psychiatry 64: 476-484. [Crossref]

6. Odgers CL, Moffitt TE, Broadbent JM, Dickson N, Hancox RJ, et al. (2008) Female and male antisocial trajectories: from childhood origins to adult outcomes. Dev Psychopathol 20: 673-716. [Crossref]

7. Yousef S, Eapen V, Zoubeidi T, Mabrouk A (2014) Behavioral correlation with television watching and videogame playing among children in the United Arab Emirates. Int J Psychiatry Clin Pract 18: 203-207.

8. Dennison BA, Russo TJ, Burdick PA, Jenkins PL (2004) An intervention to reduce television viewing by preschool children. Arch Pediatr Adolesc Med 158: 170-176. [Crossref]

9. Bar-On ME, Broughton DD, Buttross S, Corrigan S, Gedissman A, et al. (2001) Children, adolescents, and television. Pediatrics 107: 423-426.

10. Fitzpatrick C, Barnett T, Pagani LS (2012) Early exposure to media violence and later child adjustment. J Dev Behav Pediatr 33: 291-297.

11. Robertson LA, McAnally HM, Hancox RJ (2013) Childhood and adolescent television viewing and antisocial behavior in early adulthood. Pediatrics 131: 439-446.

12. Shiue I (2015) Duration of daily TV/screen watching with cardiovascular, respiratory, mental and psychiatric health: Scottish Health Survey, 2012-2013. Int J Cardiol 186: 241-246.

13. Aoki K, Downes EJ (2003) An analysis of young people's use of and attitudes toward cell phones. Telematics Inf 20: 349-364.

14. Marshall SJ, Gorely T, Biddle SJ (2006) A descriptive epidemiology of screen-based media use in youth: a review and critique. J Adolesc 29: 333-349. [Crossref]

15. Roberts DF, Foehr UG (2008) Trends in media use. Future Child 18: 11-37. [Crossref]

16. Eme RF, Kavanaugh L (1995) Sex differences in conduct disorder. J Clin Child Psychol 24: 406-426.

17. Johnson JG, Cohen P, Smailes EM, Kasen S, Brook JS (2002) Television viewing and aggressive behavior during adolescence and adulthood. Science 295: 2468-2471.

18. Kumpulainen K, Räsänen E, Puura K (2001) Psychiatric disorders and the use of mental health services among children involved in bullying. Aggressive Behav 27: 102-110.

19. Zimmerman FJ, Glew GM, Christakis DA, Katon W (2005) Early cognitive stimulation, emotional support, and television watching as predictors of subsequent bullying among grade-school children. Arch Pediatr Adolesc Med 159: 384-388.

20. Sanders MR, Dadds MR, Johnston BM, Cash R (1992) Childhood depression and conduct disorder: I. Behavioral, affective, and cognitive aspects of family problemsolving interactions. J Abnorm Psychol 101: 495-504. 
21. Dillman Carpentier FR, Brown JD, Bertocci M, Silk JS, Forbes EE, et al. (2008) Sad kids, sad media? Applying mood management theory to depressed adolescents' use of media. Media psychology 11: 143-166.

22. Romer D, Bagdasarov Z, More E (2013) Older versus newer media and the wellbeing of United States youth: results from a national longitudinal panel. Journal of Adolescent Health 52: 613-619.

23. Rey JM, Plapp JM (1990) Quality of perceived parenting in oppositional and conduct disordered adolescents. Journal of the American Academy of Child \& Adolescent Psychiatry 29: 382-385.

24. Holland R, Moretti MM, Verlaan V, Peterson S (1993) Attachment and conduct disorder: the Response Program. Can J Psychiatry 38: 420-431. [Crossref]

25. Siomos K, Floros G, Fisoun V, Evaggelia D, Farkonas N, et al. (2012) Evolution of Internet addiction in Greek adolescent students over a two-year period: the impact of parental bonding. Eur Child Adolesc Psychiatry 21: 211-219.

26. Mahoney JL, Stattin H (2000) Leisure activities and adolescent antisocial behavior: The role of structure and social context. $J$ Adolesc 23: 113-127.

27. Samek DR, Elkins IJ, Keyes MA, Iacono WG, McGue M (2015) High school sports involvement diminishes the association between childhood conduct disorder and adult antisocial behavior. Journal of Adolescent Health 57: 107-112.

28. Andersen RE, Crespo CJ, Bartlett SJ, Cheskin LJ, Pratt M (1998) Relationship of physical activity and television watching with body weight and level of fatness among children: results from the Third National Health and Nutrition Examination Survey. JAMA 279: 938-942.

29. Gadow KD Sprafkin J (1989) Field experiments of television violence with children evidence for an environmental hazard? Pediatrics 83: 399-405.

30. Etchells PJ, Gage SH, Rutherford AD, Munafò MR (2016) Prospective investigation of video game use in children and subsequent conduct disorder and depression using data from the Avon longitudinal study of parents and children. PloS one 11: e0147732.

31. Parkes A, Sweeting H, Wight D, Henderson M (2013) Do television and electronic games predict children's psychosocial adjustment? Longitudinal research using the UK Millennium Cohort Study. Arch Dis Child 98: 341-348.

32. Moller-Nehring E, Moach A, Castell R (1998) Conditions facilitating social behavior disorder in children and adolescents in a clinic referred sample. Prax Kinderpsycho Kinderpsychiatr 47: 36-47.

33. Mitrofan O, Paul M, Weich S, Spencer N (2014) Aggression in children with behavioural/emotional difficulties: seeing aggression on television and video games. BMC Psychiatry 14: 287.

34. Özmert E, Toyran M, Yurdakök K (2002) Behavioral correlates of television viewing in primary school children evaluated by the child behavior checklist. Arch Pediatr Adolesc Med 156: 910-914.

35. Blumberg SJ, Foster EB, Frasier AM, Satorius J, Skalland BJ, et al. (2012) Design and operation of the National Survey of Children's Health, 2007. Vital Health Stat 1 : 1-149. [Crossref]
36. Child and Adolescent Health Measurement Initiative (2012) "2011/12 National Survey of Children's Health (2012), Sampling and Survey Administration." Data Resource Center, supported by Cooperative Agreement 1-U59-MC06980-01 from the U.S. Department of Health and Human Services, Health Resources and Services Administration (HRSA), Maternal and Child Health Bureau (MCHB).

37. Huesmann LR, Moise-Titus J, Podolski C, Eron LD (2003) Longitudinal relation between children's exposure to TV violence and their aggressive and violent behavior in young adulthood: 1977-1992. Dev Psychol 39: 201.

38. Anderson CA, Berkowitz L, Donnerstein E, Huesmann LR, Johnson JD, et al. (2003) The influence of media violence on youth. Psychological science in the public interest 4: 81-110.

39. Eiser C, Morse R (2001) Can parents rate their child's health-related quality of life? Results of a systematic review. Quality of life research 10: 347-357.

40. Feinman JA, Feldman RS (1982) Decoding children's expressions of affect. Child Dev: 710-716.

41. Dennison BA, Russo TJ, Burdick PA, Jenkins PL (2004) An intervention to reduce television viewing by preschool children. Arch Pediatr Adolesc Med 158: 170-176. [Crossref]

42. Robinson TN, Wilde ML, Navracruz LC, Haydel KF, Varady A (2001) Effects of reducing children's television and video game use on aggressive behavior: a randomized controlled trial. Arch Pediatr Adolesc Med 155: 17-23.

43. Ford BS, McDonald TE, Owens AS, Robinson TN (2002) Primary care interventions to reduce television viewing in African-American children. Am J Prev Med 22: 106-109.

44. American Academy of Pediatrics (2016) Media Use in School-Aged Children and Adolescents. Pediatrics: 138.

45. Gorely T, Biddle SJ, Marshall SJ, Cameron N (2009) The prevalence of leisure time sedentary behaviour and physical activity in adolescent boys: an ecological momentary assessment approach. International Journal of Pediatric Obesity 4: 289-298.

46. Robinson JL, Winiewicz DD, Fuerch JH, Roemmich JN, Epstein LH (2006) Relationship between parental estimate and an objective measure of child television watching. International Journal of Behavioral Nutrition and Physical Activity 3: 1.

47. Bryant MJ, Lucove JC, Evenson KR, Marshall S (2007) Measurement of television viewing in children and adolescents: a systematic review. Obes Rev 8: 197-209. [Crossref]

48. Naslund JA, Aschbrenner KA, Marsch LA, Bartels SJ (2016) The future of mental health care: peer-to-peer support and social media. Epidemiol Psychiatr Sci 25: 113122. [Crossref]

49. Briones R (2015) Harnessing the Web: How E-Health and E-Health Literacy Impact Young Adults' Perceptions of Online Health Information. Med 20 4: e5.

50. Chou WS, Hunt YM, Beckjord EB, Moser RP, Hesse BW (2009) Social media use in the United States: implications for health communication. Journal of medical Internet research 11: e48.

Copyright: (C2018 Mukhtar F. This is an open-access article distributed under the terms of the Creative Commons Attribution License, which permits unrestricted use, distribution, and reproduction in any medium, provided the original author and source are credited. 